\title{
El camino de la experiencia estética: entre la vivencia y la comprensión*
}

\author{
The road of aesthetic experience between \\ the experience and the understanding \\ 0 caminho da experiência estética: \\ entre a vivência e a compreensão
}

Fecha de entrega: 5 de febrero de 2015

Fecha de evaluación: 5 de octubre de 2015

Fecha de aprobación: 15 de enero de 2016

Nohora Torres*

\section{Resumen}

En este artículo se pone en discusión la aparente oposición de dos enfoques que sobre la experiencia de la literatura y las artes se han definido en la tradición académica. Por un lado, la experiencia como "vivencia" en la propuesta de Jorge Larrosa (2006); por el otro se expone la "experiencia de comprensión", vista desde la perspectiva hermenéutica de Hans Jauss (1986), con esenciales aportes de la teoría de George Gadamer (1993). Esto a fin de ver los límites y posibilidades de estas dos teorías de la experiencia, de manera que se pueda tender un camino metodológico que reúna estas dos percepciones en el estudio

* Este artículo está basado en la investigación adelantada para la tesis de maestría en Estudios Literarios de la Facultad de Filosofia y Letras de la USTA. DOI: http://dx.doi.org/10.15332/s0120-8462.2016.0114.04

* * Pregrado en Estudios Literarios en la Universidad Nacional de Colombia. Magister en Estudios Literarios en la Universidad Santo Tomás. Docente de Literatura y Lengua Castellana en el Gimnasio Alessandro Volta. Correo electrónico: nohora.torres@rocketmail.com 
de la literatura, sin negar sus diferencias, más aún, evidenciando su intrínseca complementariedad.

Palabras clave: experiencia, literatura, comprensión, hermenéutica, teoría de la recepción.

\section{Abstract}

This article raises questions about the apparent opposition of two approaches that on the experience of literature and the arts have defined the academic tradition. On the one hand, the experience as "Experience" in the proposal of Jorge Larrosa (2006); on the other the "experience of understanding", viewed from the perspective of hermeneutics of Hans Jauss (1986), with essential contributions of the theory of George Gadamer (1993). This in order to see the limits and possibilities of these two theories of experience, so a methodological path that meets these two perceptions in the study of literature can be built, without denying their differences, furthermore, demonstrating its intrinsic complementarity.

Keywords: experience, literature, understanding, hermeneutics, reception theory.

\section{Resumo}

Neste artigo discute-se a aparente oposição de duas abordagens que sobre a experiência da literatura e das artes têm-se definidas na tradição académica. Por um lado, a experiência como "vivência” na proposta de Jorge Larrosa (2006); por ou outro, expõe-se a "experiência de compreensão", vista a partir da perspectiva hermenêutica de Hans Jauss (1986), com contribuições essenciais da teoria de George Gadamer (1993). Isto a fim de ver os limites e possibilidades de essas duas teorias da experiência, de maneira que se possa construir um caminho metodológico que reúna a estas duas percepções no estudo da literatura, sem negar as suas diferenças, ainda mais, mostrando a sua intrínseca complementaridade. 
Palavras-chave: experiência, literatura, compreensão, hermenêutica, teoria da recepção.

Tanto artistas, académicos y filósofos, es decir, los teóricos de las humanidades a lo largo de la historia bastante productiva de esta discusión sobre la experiencia, han estado atrincherados en dos frentes por siglos, como lo evidencia Martin Jay en su lúcido ensayo La crisis de la experiencia en la era postsubjetiva (2003) y el concienzudo estudio Song of experience (2006). Por un lado, siguiendo a este investigador, se puede identificar la experiencia entendida como vivencia erlebnis, que corresponde a "la inmediatez vital" (Jay, 2003, p. 8), precedente a la reflexión racional. En el otro extremo del espectro, se encuentra la experiencia de la comprensión, erfahrung; entendida brevemente en sus palabras como la "acumulación histórica o tradicional de sabiduría", asImismo como el "recuerdo o racionalización de lo experimentado" (Jay, 2003, p. 11). Allí se puede ubicar, desde la mayéutica socrática, hasta el enfoque hermenéutico de Georg Gadamer y la teoría de la recepción de Hans Jauss. Para empezar a dilucidar estas posiciones, comienzo por abrir el haz de significación de la palabra experiencia en la tensión entre erlebnis, que se traduce al castellano como vivencia, y su contrapartida, erfahrung, entendida como comprensión en dos autores, Jorge Larrosa y Hans Jauss. Se presenta este ejercicio de contrapunto a fin de revelar los supuestos que la teoría de la experiencia estética fundada en la recepción (en Jauss) y la propuesta teórica de Larrosa sobre la experiencia de la lectura pueden revelar sobre cómo llegar a comprender la relación de la literatura y las artes en la experiencia que hace de ella.

Se parte de la experiencia vivida, erlebnis. Esa que al parecer, se suele descontar gratuitamente junto con el respirar o el existir, y así sucede... hasta que pasa algo. Ahora, surge la primera cuestión: ¿̇realmente se considera una experiencia cada segundo que pasa del existir cotidiano? Si se entiende ese pasar de la vida como el transcurrir del agua que corre por un río, el río del tiempo, metáfora del continuum temporal, famosa desde Heráclito hasta Paul Valery en su Eupalinos o el arquitecto, casi se puede ver a Sócrates observando el fluir del acontecer humano junto a Fedro. Ambos personajes trasplantados por Valery del diálogo platónico a la modernidad, se enfrentan a la idea del sin sentido del acontecer vital. Así Valery en la voz de Sócrates plantea el acontecer cotidiano como la ausencia de experiencia vivida cuando dice:

El que aquí ves es el río del tiempo (...). Ese gran flujo, con todo, se halla compuesto de todas las cosas que hayas podido conocer esa faja, accidentada, 
inmensa, que se precipita sin espera, se lleva cuanto hay hacia la nada (Valery, 2001, p. 3).

En efecto, en el apartado anterior, Paul Valery demuestra que la experiencia no es igual a la inconsciencia de este transcurrir vital que se suele llamar vida diaria; de hecho, si se recurre a la memoria, se comprenderá que la experiencia vivida acontece como ese algo que de un golpe de oreja al modo de Neruda, despierta a los hombres de este estado de cuerpos dormidos a la conciencia del transcurrir vital.

Precisamente la experiencia para Jorge Larrosa (2006) es algo que pasa, mas no que pasa como cosa externa, aquello por un lado y el sujeto por el otro, sin afectarse. Por el contrario, la experiencia vital no solo aparece para suspender el pasar del tiempo, sino que además, atraviesa el sujeto de parte a parte, le transforma, "porque la vida humana es la de un ser solo a medias formado a la de un ser que está siempre en camino de su forma propia y que justamente por eso es capaz de transformación, de metamorfosis" (p. 79). Por ello, se podría acudir incluso a su forma pasiva, patética, como algo como de paso por el sujeto. Cuando algo le pasa, sucede que esta experiencia le resquebraja la ilusión de impasividad oculta en el fluir temporal cotidiano y lo lanza de improviso a la vulnerabilidad y a la pasión del ser expuesto al devenir. De esta forma Larrosa afirma que la esencia dinámica de la experiencia vivida está fundada en el acontecer de algo externo que empuja al sujeto siempre fuera de sí:

El llegar a ser lo que se es no está del lado de la lógica de la identidad (...), sino del lado de la lógica des-identificadora de la invención (...). Si el inicio del Bildung roman tiene la forma de la negación, su trama tiene la forma de la experiencia. Y la experiencia es lo que nos pasa, y el modo como nos ponemos a nosotros mismos en lo que nos pasa. La experiencia es un paso, un pasaje (Larrosa, 2006, p. 89).

Luego, la experiencia surge de esta acción que cae de improviso sobre el sujeto beneficiario o perjudicado, le aturde, le abre una fisura en ese caparazón del ser impertérrito que diariamente se endurece; y de pronto, le deja expuesto ante el camino que se abre ante sus pies. He aquí que sin fijarse, paso a paso, se llega al otro extremo del espectro de la experiencia como "un salir afuera y pasar a través". En su nombre germánico, erfahrung tiene la misma raíz que fahren, que se traduce normalmente por viajar. "Porque la experiencia es lo que le pasa a un ser en tránsito" (Larrosa, 
2006). Así, aparece para Larrosa la forma del camino que se abre a los pies del sujeto en la distancia, que le lleva a pensar la experiencia "como un cauce que albergue ese transitar propio de la vida humana” (Larrosa, 2006, p. 87).

\section{De la experiencia vivida a la experiencia comprendida}

Allí donde se debe hacer una elección de destino, se acaba el camino y se abandona al viajero ante lo desconocido. En el surgimiento de la duda, aparece la experiencia de la comprensión. Para Georg Gadamer, erfahrung, el esfuerzo de comprensión, empieza así, cuando alguien encuentra algo que le resulta extraño, es decir, como "algo que no encaja en nuestra expectativa de comprensión y que por eso nos desconcierta" (Gadamer, 1998, p. 182). De manera semejante a como lo plantea Gadamer en "esta incompatibilidad con las expectativas pre-esquemáticas de nuestra orientación del mundo, que da que pensar" (Gadamer, 1998, p. 182). Para Jauss, esto se da en la negación del horizonte conocido de valores de la realidad cotidiana. Luego, esta crisis en el horizonte conocido del sujeto, es el motivo que lanza al viajero a la búsqueda de un sentido nuevo, desconocido, como lo explica Gadamer (1993):

\footnotetext{
El sentido no es esa totalidad disponible sobre la que siempre hemos estado de acuerdo, un mundo de sentido más allá de la realidad, el otro mundo platónico que desde Nietzsche, ya no debería existir. El sentido es como la lengua nos enseña, dirección. Se mira en una dirección, al igual que las agujas del reloj se mueven en un sentido determinado. Así, todos, cuando se nos dice algo, tomamos la dirección del sentido (p. 149).
}

Para Jauss, erfahrung, esta búsqueda de sentido se aplica especialmente a la experiencia del objeto estético. En efecto, Jauss se refiere a la experiencia de disfrute o goce estético que se da por la negación de los valores de la existencia cotidiana. Se entiende por esto, la actitud negativa de la experiencia estética literaria y artística que rechaza los valores e intereses establecidos como normales en la experiencia vital del individuo. Luego, la experiencia literaria propuesta por Jauss (2002) corresponde a "la actitud de goce con el arte para y desde la liberación” (p. 5). Pues, el goce (geniessen) producido por la obra artística en el sujeto se da por la liberación de la conciencia imaginativa activa en la contemplación de la obra que la desata, gracias precisamente 
a ese encuentro de horizontes generado por el enfrentamiento con lo desconocido y la formulación de la pregunta, que se desarrolla en el diálogo con la obra de arte.

Por consiguiente, no de otra forma, sino cuando se pone entre signos de interrogación y actitud de apertura el horizonte de lo propio, y se enfrenta a lo ajeno, se puede preguntar la dirección para llegar a un sentido que sea común. Por ello, consecuentemente, se empieza por buscar señales en lo desconocido, pistas que guíen en el sentido oculto entre nuestro horizonte conocido y lo otro. Luego, de este movimiento entre los dos, sobreviene el sentido construido en conjunto. Mas no por ello se desprecia la memoria de las experiencias pasadas y las rutas recorridas, por el contrario, estas sirven al que incursiona en un paisaje desconocido como puntos de referencia para establecer una posición y para orientarse en una dirección. Tanto Gadamer como Jauss, no desechan el horizonte de la experiencia pasada, antes bien, lo ponen como base del método dialógico de la experiencia en el que se parte del horizonte propio hacia el ajeno, reconociéndolo como irreductiblemente otro.

Desde esta perspectiva, cuando el sujeto de la experiencia se encuentra perdido, no se establece una condena inamovible a la nada del sentido en ese río del tiempo que presentó ya Paul Valery, sino lo que se propone es un momento de paso, el de la encrucijada que le llevará a “devenir otro”. Así, en una época en que el sentido absoluto se ha derrumbado, renace la experiencia de búsqueda del sentido como ansia o necesidad de dirección en nuestras propias travesías finitas, históricas, humanas. Es en medio de la incertidumbre donde esto se da, pues no hay más remedio que afrontar la duda y elegir un sentido para seguir, aceptando el riesgo en la elección y sus consecuencias. De esta forma, como lo señala Gadamer, tanto la experiencia de diálogo vivida con el otro, como la experiencia comprendida de la poesía, entendida como el diálogo del sujeto con el texto, le abre la conciencia de los límites de su propio horizonte ante la alteridad: "el poema que comprendemos y cuyo testimonio nunca se agota, y el diálogo en el que nos encontramos y que, como diálogo infinito del alma consigo misma, nunca llega a su término, son formas de esa concepción de sentido" (Gadamer, 1993, p. 149).

En consecuencia, el fin de este ejercicio dialógico hermenéutico, resulta en la comprensión, no como respuesta final a la pregunta que lo contextualiza, sino en la apertura de sentido que logra la pregunta hallada, de la cual es respuesta el texto, y su repercusión actualizada en el horizonte mismo del lector, fenómeno que denomina Gadamer (1999), fusión de horizontes: “forma parte de la verdadera comprensión, 
el recuperar los conceptos de un pasado histórico de manera que contenga al mismo tiempo, nuestro propio concebir" (p. 450).

Asimismo, Jauss asume el arte y la sociedad en un ejercicio dialéctico donde la obra de arte es inquirida constantemente por los lectores que la actualizan con su interacción; y de esta manera, la constituyen como una respuesta posible y abierta en las circunstancias históricas del acontecer de la experiencia estética. Con todo, Jauss se distancia de Gadamer en tanto que su propuesta se manifiesta en la comprensión del efecto de la obra como manifestación histórica acaecida en el acontecer de un grupo social lector/espectador, esencia esta, de la función comunicativa de la experiencia estética. Por ende, se subraya que si bien la historicidad es un rasgo estructurante presente en el ejercicio hermenéutico literario dilucidado por Gadamer en la reconfiguración de horizontes de comprensión, es Jauss quien lo asume en la contrastación de horizontes de expectativas.

Así, para Jauss, la reconfiguración del horizonte histórico del efecto de la obra es siempre contingente y parcial. Por esta razón, para él es importante considerar siempre la experiencia como el acontecer del encuentro del lector/espectador con la obra, donde este participa en la construcción del sentido de la obra misma. Justamente a este espacio de participación es lo que Jauss determina como posibilidad comunicativa de la experiencia estética. Esta función comunicativa, consiste no solo en una valoración o juzgamiento por los lectores, sino que este juicio implica una reconfiguración del efecto significativo de la obra en el mundo. Si se comprende esta función comunicativa, se hace evidente que Jauss, adapta la pregunta de Gadamer como principio de la experiencia estética, dándole importancia a la experiencia comunicable, sensus comunis, en donde funda su teoría de la experiencia estética (Jauss, 1989, p. 21).

Por su parte, Gadamer (1999) afirma la función comunicativa de la experiencia en "la coincidencia que ya no es mi opinión o la tuya, sino una interpretación común del mundo que posibilita la solidaridad moral y social” (p. 185). Mas a esto, Jauss añade la contrastación controlada de horizontes del lector en los límites que le impone la consciencia estructurante del horizonte construido de la obra como alteridad, idea que retoma de Bajtín; de esta forma, enunciando la negatividad de la otredad de la obra, se establece la distancia necesaria que posibilita la trascendencia de la dimensión comunicativa y catártica de la experiencia estética como experiencia vital y cognitiva de las artes: 
La experiencia estética que transforma a quien la realiza no es únicamente la experiencia de una verdad instanciada en la obra de arte, sino también - y en mi opinión primordialmente- la experiencia de comprender el carácter ajeno del texto como otro modo de existir (lit.: "un ser otro" [Andersein]), y como una posibilidad de ser otro (Ut: "poder-ser-otro" [Andersein konnen]) (Jauss 1989, p. 4).

=En consecuencia, ese lugar comunicable que resulta ser la experiencia erfahrung, es para Jauss, un espacio para la crítica a las certezas anquilosadas como verdades autorizadas, como también es la oportunidad para transformarlas, para imponer nuevos modelos de sentido. Así, ambas fuerzas que juegan en la obra de arte, tanto la positiva de identidad y la negativa de extrañamiento, crean la tensión de la ambigüedad que fundamenta la experiencia estética y abre la posibilidad de la transformación del horizonte de expectativas del lector y el horizonte del efecto de la obra en el mundo.

\section{Camino sobre el horizonte que nos une}

Ahora, a partir de esta visión anteriormente esbozada como camino desde la experiencia vivida a la experiencia de comprensión se aborda la pregunta que ha estado creciendo desde un principio de este dis-curso de la experiencia: ¿ cómo se puede ofrecer la experiencia de la literaturas y las artes como un método-camino de comprensión que ha de trazar cada uno sin ser ajeno a su propia vivencia? El peligro en dar una respuesta fácil es palpable, pues si se inclina por la experiencia estética de la lectura literaria solo como vivencia, se corre el riesgo de quedar atrapado en el silencio de la incomprensión o la superficialidad de lo momentáneo. Por otro lado, si se tiende a la universalidad de la comprensión, se cierra el paso al nacimiento de la pregunta, y por lo tanto a la experiencia misma del sujeto. Así que ante el peligro de la caída de un lado o el otro, se sugiere afrontar el camino medio, al filo de la nada y el todo como alguna vez dijo Pascal. A propósito de un método-camino de la experiencia de las artes que contenga tanto la vivencia como la comprensión, María Zambrano manifiesta que (citado por Larrosa, 2006):

El método ha debido estar siempre desde un principio en una cierta y determinada experiencia, que por virtud de aquel, llega a cobrar cuerpo y forma, mas ha sido necesaria cierta aventura y hasta una cierta perdición en la experiencia, 
cierto andar perdido el sujeto en quien se va formando. Un andar perdido que será luego libertad (p. 72).

En la teoría de Jauss se puede dilucidar este camino medio en el planteamiento incluido en su obra Historia de la literatura como provocación (2008), pues desde allí ha desarrollado la propuesta de la experiencia de comprensión de la obra de arte y por ende, de la literatura como acontecimiento histórico con función social, comunicativa y transformadora. Esto se evidencia cuando explica que: "allí donde esta entra en el horizonte de expectativa de su práctica vital, preforma su comprensión del mundo, con ello, también incide en su comportamiento social" (Jauss, 1975, p. 76). Para lograr esta experiencia vital y cognitiva del arte, como ya se ha notado, Jauss recurre al método dialógico de pregunta-respuesta tomado de la hermenéutica de Gadamer, y lo adapta en el fenómeno de contrastación de horizontes de expectación, donde el horizonte de la obra es condicionado por el juicio que hace de esta el público en los momentos tanto de producción como de recepción, y en las subsecuentes lecturas a lo largo del devenir histórico.

En el artículo El lector como instancia de una nueva historia de la literatura (1987), Jauss aclara el concepto de horizonte de expectación gracias a la contribución de Wolfgang Iser, quien aporta la diferencia en el encuentro dialógico del horizonte de expectativas intraliterario y el horizonte extraliterario. De esta manera, Jauss asume el horizonte extraliterario como correspondiente a la comprensión previa de mundo del lector explícito de Iser, que incluye las "expectativas concretas procedentes del horizonte de sus intereses, deseos, necesidades y experiencias, condicionado por las circunstancias sociales, las específicas de cada estrato social y también las biográficas" (Jauss, 1975, p. 77). A este horizonte extraliterario que constituye al lector explícito, se le opone el lector implícito que resulta de la construcción del horizonte intraliterario, empleando las orientaciones previas que acompañan al texto, entendidas en la “comprensión previa de los géneros, de la forma y la temática de las obras anteriormente conocidas" (Jauss, 1975, p. 76). Así, este lector intraliterario corresponde a la "función del lector prescrita literariamente", la cual es objetivable en las estructuras del texto. De tal forma para Jauss, una vez se ha constituido la función del lector implícito, se pueden descubrir con mayor seguridad las estructuras de comprensión previa, así como las proyecciones ideológicas que han condicionado la comprensión de una obra por un grupo social en una situación histórica. Luego, solo después que se construye la configuración del horizonte de expectativas intraliterario, el lector 
situado históricamente en el acontecimiento de la lectura puede actualizar el sentido potencial de la obra, y por consiguiente; se da la fusión de horizontes en la inserción de la comprensión previa de mundo (del lector) en el marco de referencia de los antecedentes literarios de recepción (Jauss, 1975).

La pregunta así construida del horizonte intraliterario no se agota, sino que hace parte de otras tantas preguntas posibles que, justamente evidencian la potencialidad de significación de la obra literaria en la historia del efecto de la obra. La pregunta reconfigurada en el horizonte intraliterario, cuestiona la consciencia del lector explícito en su horizonte vital, evidenciando la "apertura aparentemente inamovible del orden social a nuevas expectativas" (Jauss, 1986, p. 324). De este modo, el movimiento de ida y venida en el encuentro de horizontes no se cierra en una acción terminada, sino queda abierto en un impulso ad infinitum a una nueva reconfiguración en cada experiencia como acontecimiento de lectura. De allí que en este trayecto de la experiencia vivida a la experiencia comprendida habría que plantearse la advertencia de la que hace eco Martín Jay del propio Gadamer: "ser experimentado no significa que uno sepa algo de una vez para siempre y se rigidice en tal conocimiento (...). Una persona experimentada es no dogmática. Más bien, uno se abre a nuevas experiencias" (Gadamer, 2003, p. 12). Lo anterior concordaría con la propuesta de Larrosa de un ser en continuo devenir.

Es así que la experiencia de las artes como travesía vivida y comprendida, obliga a pensar en un viaje por la geografía interna, puesto que dibuja un trayecto siempre inacabado desde un estado del ser de partida y una proyección de un punto de llegada al otro ser que siempre está tras esta. Ese que apenas si se reconoce al voltear a mirar hacia atrás y ve las huellas que ha dejado a su paso, las huellas que paso a paso, han surcado un rostro curtido, experimentado.

Larrosa, por su parte, propone la pregunta sobre lo que no está dicho como método de apertura a la experiencia de la lectura, no como una develación de un sentido ya preestablecido, sino como una búsqueda de sentido siempre nueva, construida en el acontecer de la lectura: "pero aprender a leer no es solo adquirir la capacidad de entender lo que el texto dice, sino ser capaces de escuchar, en lo dicho, lo que da qué decir, lo que queda por decir" (Larrosa, 2006, p. 57). En consecuencia, la experiencia de la lectura literaria no se hace para permanecer cerrado sobre sí mismo, ni para ver en ella el reflejo de lo propio, implica por el contrario, aprender a escuchar en la lectura la voz de la otredad. Por consiguiente, resulta necesario al lector buscar 
en actitud de escucha la pregunta que le permita suspender el sentido del mundo preestablecido, y abrirse a la inquietud que hace perder la solidez de la certeza de un sentido de mundo, para que se abra a una nueva posibilidad de significación.

Así el ejercicio de la experiencia de la literatura sería "mantener abierto un espacio en el que cada uno pueda encontrar su propia inquietud" (Larrosa, 2006, p. 32); de manera semejante a como lo plantea Jauss con el método dialógico de la pregunta hermenéutica. Así, más que una forma de aprehender un saber, este método consiste en mostrar una intención de escucha, es decir, una actitud de apertura a la pregunta que ponga en cuestión tal como lo afirma Jauss (citado por Capdevilla, 2005) "los horizontes solidificados, las legitimaciones ideológicas de otros submundos de sentido" (p. 323).

Como ya se ha visto tanto en la teoría formulada por Jauss, fundada en la hermenéutica de Gadamer, así como en la propuesta de Larrosa, el camino de la experiencia de las artes, empieza por sacar al sujeto de la ruta conocida, y le obliga a asumir la consciencia histórica y mortal de su experiencia de comprensión. Le lleva a afirmar pues en su experiencia vivida, que el impulso de la experiencia de las artes y la literatura no parte de un conocimiento dado como prejuicio de verdad, aun cuando por experiencia parezca conocerse ya el camino recorrido, y que es necesario asumirla ante la posibilidad de abrirse de nuevo a la interpretación, a la incertidumbre, a la vivencia actualizada con el otro. De allí la necesidad de hacerle una grieta a ese objeto de conocimiento que es en apariencia hermético, finito, empaquetado por la tradición de verdad que representa la experiencia del investigador en literatura, y romperlo en pedazos, romper con ello las certezas; a fin de permitir que algo pase, dejar la herida abierta para que surja de la incertidumbre en ese espacio abierto, la experiencia de las artes.

Con el planteamiento teórico sobre la experiencia de las artes presentado no se niega la tensión entre la concepción de la experiencia estética como vivencia o como comprensión. Por el contrario, se evidencia la necesidad de apreciar esta oposición paradigmática, dado que ambas a su manera, reivindican la experiencia de las artes como algo que hace parte de la vida de cada uno, que le conmueve, que le cambia, pero así mismo, como aquello que le permite reestructurar su horizonte de sentido en el diálogo con la obra. Así, la visión de la experiencia de las artes que se propone como camino metodológico de estudio de la obra literaria y artística, se configura entre dos pilares teóricos que se encuentran en el arco de un mismo fenómeno, el 
acontecer histórico de la experiencia en el individuo que la vive y que la comprende. Por ende, como se ha visto, la experiencia estética resulta ante todo una realidad nodal, un punto de convergencia, que requiere ser comprendida como tal.

Además, como afirma Jauss, la historicidad del encuentro de la obra y su público receptor, lleva implícito el hecho de que la experiencia de las artes ha tejido una historia, una tradición de recepción, sobre la cual se sustenta y se modifica tanto la obra misma como la comunidad en que sucede; dando relevancia a la sucesión de lecturas a través de la cuales se expone la naturaleza dinámica y comunicativa del arte. Por consiguiente, si se acepta el principio de particularidad de la experiencia, no se está relativizando la experiencia de la literatura y las artes; antes bien, se posibilita un espacio de diálogo entre los sujetos que la perciben. De manera semejante, Larrosa (2006) se refiere a la necesidad de crear un espacio de escucha, donde se pongan en común las preguntas de cada lector desde su particular horizonte vital, y desde su reconstrucción del horizonte de la obra, que dé lugar a una retroalimentación de la experiencia abierta en los diversos universos de sentido.

Esta reflexión teórica, resulta por tanto en una invitación a tender un puente, paso a paso, ante el abismo que se abre entre la teoría de la experiencia estética como conocimiento, y aquella experiencia estética particular que ocupa a cada uno, en su vivencia docente y aprendiz de la literatura. Es así una oportunidad para suspender el trajín diario de las clases un momento en su cauce a fin de ponerlo a dialogar junto con la teoría y mirar qué posibilidades de sentido puede cobrar para el estudio de la literatura. 


\section{Referencias}

Capdevila, P. (2005). Experiencia estética y hermenéutica. Un diálogo entre Inmanuel Kant y Hans Robert Jauss, tesis de doctorado. Universidad de Barcelona. Recuperado de http://www.tdx.cat/handle/10803/5169

Gadamer, H. G. (1993). Poema y diálogo. Barcelona: Gedisa.

Gadamer, H. G. (1998). Lenguaje y comprensión. Verdad y método II. Salamanca: Sígueme.

Gadamer, H. G. (1999). Verdad y método. Salamanca: Sígueme.

Jay, M. (2003). La crisis de la experiencia en la era postsubjetiva. Santiago de Chile: Ed.UDP.

Jay, M. (2005). Song of experience. Modern American and European variations on a universal theme. Bekerley: University of California Press.

Jauss, H. (1986). Experiencia estética y hermenéutica literaria. Madrid: Taurus.

Jauss, H. (1987). El lector como instancia de una nueva historia de la literatura. En José Antonio Mayoral (coord.). Estética de la recepción, 59-86. España: Arco Libros.

Jauss, H. (1989). Respuesta a Claude Pichet. Revista Universidad Nacional Ideas y Valores, 81, 17-25. Recuperado de http://www.revista.unal.edu.co/index.php/idval /search/authors/view?firstName=Hans\&middleName=Robert\&lastName=Jauss\& affiliation $=\&$ country $=[14 / 10 / 13]$

Jauss, H. (2002). Pequeña apología de la experiencia estética. Barcelona: Paidós.

Jauss, H. (2008). Historia de la literatura como una provocación a la ciencia literaria. En Rall, D., Franco, S., et al., (eds.). En busca del texto. Teoría de la recepción literaria, 55-57. México: Universidad Nacional Autónoma de México.

Larrosa, J. (2006). La experiencia de la lectura. México: Fondo de Cultura Económica.

Valery, P. (2001). Eupalinos o el arquitecto; el alma y la danza. Madrid: Antonio Machado. 